\title{
PENGARUH KEPIMPINAN KEWIRAUSAHAAN DAN MOTIVASI TERHADAP KEPUASAN KERJA KARYAWAN PADA UNIVERSITAS SERANG RAYA
}

\author{
Hamdan \\ Fakultas Ekonomi dan Bisnis Universitas Serang Raya \\ Email: hamdanunsera@gmail.com
}

\begin{abstract}
Abstrak: Pemimpin yang memiliki jiwa kewirausahaan atau kepemimpinan kewirausahaan dan motivasi mutlak diperlukan sebagai intangible culture, suatu kemampuan structural non fisikal yang mampu menggerakan sosok fisikal, berani mengambil resiko dan mengutamakan prestasi kerja. sehingga penelitian ini bertujuan untuk mengetahui Pengaruh Kepimpinan Kewiarausahaan dan Motivasi Terhadap Kepuasan Kerja Karyawan Pada Universitas Serang Raya. Penelitian ini menggunakan metode deskriptif dan berupa angket (kuesioner) yang disebar kepada 77 (tujuh puluh tujuh) responden yang menjadi sampel penelitian ini, data tersebut berasal dari populasi yang berdistribusi normal dan memiliki variansi yang sama.
\end{abstract}

Teknik pengumpulan data menggunakan kuesioner dengan pengukuran skala Likert. Penentuan sampelnya berdasarkan sampel jenuh. Analisis datanya dengan Uji Instrument dan Uji Hipotesis.

Keywords: Kepimpinan Kewirausahaan, Motivasi, intangible culture, Kepuasan Kerja, dan Jiwa Kewirausahaan.

Abstract: A leader who has an entrepreneurial spirit or entrepreneurial leadership and motivation is absolutely necessary as an intangible culture, a non-physical structural capability that is able to move a physical figure, dare to take risks and prioritize work performance. so this study aims to determine the Effect of Entrepreneurship Leadership and Motivation on Employee Job Satisfaction at Serang Raya University. This study used a descriptive method and in the form of a questionnaire (questionnaire) distributed to 77 (seventy seven) respondents who were the sample of this study, the data came from populations that were normally distributed and had the same variance

The technique of collecting data uses a questionnaire with a Likert scale measurement. Determination of the sample based on saturated samples. Analysis of the data using the Instrument Test and Hypothesis Test.

Keywords: Entrepreneurship Leadership, Motivation, Intangible Culture, Job Satisfaction, and Entrepreneurship Soul. 


\section{PENDAHULUAN}

Setiap organisasi, pemimpin yang memiliki jiwa kewirausahaan merupakan salah satu faktor utama dalam mendukung kesuksesan organisasi untuk mencapai tujuan, keberhasilan atau efektifitas kepemimpinan tidak saja diukur bagaimana memberdayakan bawahannya tapi juga kemampuannya menjalankan kebijakan melalui cara atau gaya Kepemimpinannya, gaya kepemimpinan sangat tergantung pada karaketeristik individu pemimpin yang memiliki jiwa kewirausahaan dalam menggerakan bawahan berdasarkan fungsinya sebagai atasan. Peran kepemimpinan yang sangat strategis dan penting bagi pencapaian visi, misi, dan tujuan organisasi, merupakan salah satu motif yang mendorong manusia untuk selalu menyelidiki seluk-beluk yang terkait dengan kepemimpinan. Adapun Kewirausahaan adalah suatu proses dalam mengerjakan sesuatu yang baru atau kreatif dan berbeda (inovatif) yang bermanfaat dalam memberikan nilai lebih.atau dengan kata lain kewirausahaan adalah suatu keberanian untuk melakukan upaya upaya memenuhi kebutuhan hidup yang dilakukan oleh seseorang atas dasar kemampuan dengan cara memanfaatkan segala potensi yang dimiliki untuk menghasilkan sesuatu yang bermanfaat bagi dirinya dan orang lain, seseorang dianggap wirausaha bila sudah memenuhi definisi wirausaha itu sendiri. Pemimipin kewirausahaan yang baik merupakan pemimpin yang selalu berorientasi ke depan dalam memimpin para karyawannya dengan baik. Para wirausaha memiliki gaya kepemimpinan yang berbeda, mereka mengembangkan gaya kepemimpinan mereka sendiri sesuai dengan karakter pribadi mereka dalam memajukan.

Kepemimpinan di Universitas Serang Raya sepenuhnya menerapkan fungsifungsi kepemimpinan seperti fungsi instruktif yang belum sepenuhnya di laksanakan, komunikasi atasan dengan bawahan yang tidak terjalin dengan lancar, partisipasi atasan terhadap bawahan yang masih rendah, fungsi pendelegasian yang belum sepenuhnya dilaksanakan sehingga pengambilan keputusan tidak bisa di laksanakan dengan cepat, masih kurangnya pengarahan, koordinasi dan pengawasan dari pimpinan. karena pimpinan belum sepenuhnya melakukan fungsi-fungsi kepemimpinan dengan baik. Motivasi didefinisikan oleh beberapa peneliti sebagai ukuran dari kekuatan identitas dan keterlibatan karyawan dalam tujuan dan nilai-nilai organisasi. Motivasi didapatkan sebagai indikator yang lebih baik dari "leavers" dan "stayers" daripada kepuasan kerja. Penelitian lain mendapatkan bahwa kepuasan kerja berkaitan dengan lingkungan tugas, sementara motivasi berkaitan dengan pencapaian pada pemberdayaan organisasi. Dengan motivasi yang diberikan, diharapkan kepuasan kerja dari karyawan akan meningkat, mendefinisikan motivasi sebagai sebuah sikap yang merefleksikan loyalitas karyawan kepada organisasi dan merupakan suatu proses berkelanjutan dimana anggota organisasi mengungkapkan perhatian mereka terhadap organisasi, terhadap keberhasilan organisasi serta kemajuan yang berkelanjutan.

Menurut Tangkilisan (2005:78) kepemimpinan dalam suatu organisani atau bidang kerja memiliki fungsi yang berbeda antara suatu organisasi yang satu dengan lainnnya, fungsi pemimpin pada dasarnya tergantung dari beberapa hal terdiri dari situasi sosial dalam organisasi, karakteristik pemimpin dan jumlah anggota.Selain itu dalam penelitian ini membahas mengenai fungsi utama yang 
harus dimiliki seorang pemimpin. Menurut Siagian (1989) mengenai pemahaman tentang teknik dan cara untuk mengukur tingkat kepuasan kerja pegawai, dimana kepuasan kerja merupakan sikap emosional pegawai dimana mencintai dan senang terhadap pekerjaan yang diembannya, dimana sikap ini dicerminkan oleh moral kerja, kedisiplinan dan prestasi kerja yang dimiliki oleh setiap pegawai. Kepuasan kerja merupakan suatu rasa gembira dan memberikan nilai positif terhadap suatu penilaian terhadap suatu pekerjaan.

Adapun tingkat kepuasan kerja karyawan di Universitas Serang Raya seperti pemenuhan kebutuhan hidup yang belum tercukupi dengan baik dikarenakan upah minimum yang masih kecil sehingga mengakibatkan tingkat kepuasan individu belum tercapai.

\section{KAJIAN TEORI}

Menurut Tangkilisan H.N.S (2005:78) Kepimpinan memiliki fungsi dalam suatu kelompok kerja yang satu dengan kelompok kerja yang lain. Hal ini disebabkan pemimpin memiliki fungsi dalam suatu organisasi, situasi sosial dalam organisasi, karakteristik pemimpin dalam suatu kelompk kerja. Selanjutnya Tangkilisan ( 2005:30) menjelaskan mengenai ada beberapa fungsi paling penting dalam mengemban suatu tugas oleh pemimpin sebagai berikuy: menetapkan, mengorganisasikan, memotivasi dan berkomunikasi, evaluasi,dan mengembangkan bawahan termasuk dirinya sendiri.Oleh karena itu, seorang pemimpin berfungsi mempersiapkan sumber daya yang handal sehingga diperlukan suatu dukungan dan motivasi dari anggota.

Kepimpinan yang berhasil akan mampu memberikan arahan dan memberikan contoh kepada seluruh karyawan untuk mencapai hasil dan tujuan tujuan yang ingin dicapai. Karena pemimpin harus mampu memberikan contoh dalam hal segala hal, seperti mementingkan kepentingan tujuan bersama diatas kepentingan pribadi.Selain itu pemimpin mampu berkomunikasi dengan seluruh pihak, sehingga dapat terjalin komunikasi yang baik antar seluruh karyawan. Pemimpin juga dalam proses pengambilan keputusan harus benar benar melihat dari segala aspek.Selaim itu pemimpin juga harus memiliki kualitas pribadi lebih unggul daripada bawahannya, selain itu pemimpin harus dapat memberikan dorongan kepada bawahanya untuk maju.

\section{METODE PENELITIAN}

Metode Pengolahan Data. Penelitian ini akan menggunakan metode survey dengan pendekatan kuantitatif menggunakan teknik analisis data menggunakan skla likert terdiri dari pengujian validitas, pengujian reliabilitas, dan uji asumsi klasik. Uji Normalitas, Uji Linieritas, Uji Heterokedastisitas, Analisis Rata-Rata Penafsiran, Analisis Koefisien Determinasi, Analisis Regresi, Menguji Hipotesis (Uji ”t'), Uji F. 


\section{HASIL DAN PEMBAHASAN}

\section{A. Uji Instrument} Uji Validitas

Tabel 1.Hasil Uji Validitas Variabel Kepemimpinan $\left(\mathrm{X}_{1}\right)$ Item-Total Statistics

\begin{tabular}{|lrrrrr|}
\hline & $\begin{array}{c}\text { Scale Mean if } \\
\text { Item Deleted }\end{array}$ & $\begin{array}{c}\text { Scale } \\
\text { Variance if } \\
\text { Item Deleted }\end{array}$ & $\begin{array}{c}\text { Corrected } \\
\text { Item-Total } \\
\text { Correlation }\end{array}$ & $\begin{array}{c}\text { Squared } \\
\text { Multiple } \\
\text { Correlation }\end{array}$ & $\begin{array}{c}\text { Cronbach's } \\
\text { Alpha if Item } \\
\text { Deleted }\end{array}$ \\
\hline X1.1 & 42.00 & 5.526 & .380 & .326 & .728 \\
X1.2 & 42.05 & 5.024 & .608 & .742 & .692 \\
X1.3 & 42.05 & 5.366 & .437 & .603 & .720 \\
X1.4 & 42.01 & 5.776 & .257 & .570 & .746 \\
X1.5 & 42.14 & 5.203 & .496 & .525 & .710 \\
X1.6 & 41.91 & 5.610 & .396 & .375 & .726 \\
X1.7 & 41.92 & 5.415 & .489 & .404 & .713 \\
X1.8 & 42.13 & 5.351 & .426 & .577 & .722 \\
X1.9 & 42.00 & 5.816 & .243 & .460 & .748 \\
X1.10 & 41.86 & 5.808 & .338 & .278 & .734 \\
\hline
\end{tabular}

\begin{tabular}{|cccc|}
\hline No & $\mathrm{r}_{\text {hitung }}$ & $\mathrm{r}_{\text {tabel }}$ & Keterangan \\
\hline 1 & 0.380 & 0.224 & Valid \\
2 & 0.608 & 0.224 & Valid \\
3 & 0.437 & 0.224 & Valid \\
4 & 0.257 & 0.224 & Valid \\
5 & 0.496 & 0.224 & Valid \\
6 & 0.396 & 0.224 & Valid \\
7 & 0.489 & 0.224 & Valid \\
8 & 0.426 & 0.224 & Valid \\
9 & 0.243 & 0.224 & Valid \\
10 & 0.338 & 0.224 & Valid \\
\hline
\end{tabular}

Tabel 2.Hasil Uji Validitas Variabel Motivasi $\left(\mathbf{X}_{2}\right)$ Item-Total Statistics

\begin{tabular}{|lccccc|}
\hline & $\begin{array}{c}\text { Scale } \\
\text { Mean if } \\
\text { Item } \\
\text { Deleted }\end{array}$ & $\begin{array}{c}\text { Scale } \\
\text { Variance if } \\
\text { Item Deleted }\end{array}$ & $\begin{array}{c}\text { Corrected } \\
\text { Item-Total } \\
\text { Correlation }\end{array}$ & $\begin{array}{c}\text { Squared } \\
\text { Multiple } \\
\text { Correlation }\end{array}$ & $\begin{array}{c}\text { Cronbach's Alpha } \\
\text { if Item Deleted }\end{array}$ \\
\hline X2.1 & 40.10 & 14.884 & .241 & .143 & .692 \\
X2.2 & 40.38 & 12.817 & .505 & .513 & .644 \\
X2.3 & 40.16 & 13.554 & .424 & .510 & .662 \\
X2.4 & 40.43 & 13.301 & .365 & .663 & .674 \\
\hline
\end{tabular}




\begin{tabular}{|llllll|}
\hline X2.5 & 40.21 & 13.877 & .582 & .493 & .647 \\
X2.6 & 40.18 & 14.703 & .248 & .531 & .692 \\
X2.7 & 40.32 & 12.959 & .438 & .522 & .658 \\
X2.8 & 40.62 & 13.633 & .287 & .329 & .692 \\
X2.9 & 40.05 & 14.918 & .265 & .574 & .688 \\
X2.10 & 39.97 & 15.236 & .293 & .456 & .685 \\
\hline
\end{tabular}

\begin{tabular}{|cccc|}
\hline No & $\mathrm{r}_{\text {hitung }}$ & $\mathrm{r}_{\text {tabel }}$ & Keterangan \\
1 & 0.241 & 0.224 & Valid \\
\hline 2 & 0.505 & 0.224 & Valid \\
3 & 0.424 & 0.224 & Valid \\
4 & 0.365 & 0.224 & Valid \\
5 & 0.582 & 0.224 & Valid \\
6 & 0.248 & 0.224 & Valid \\
7 & 0.438 & 0.224 & Valid \\
8 & 0.287 & 0.224 & Valid \\
9 & 0.265 & 0.224 & Valid \\
10 & 0.293 & 0.224 & Valid \\
\hline
\end{tabular}

Tabel 3. Hasil Uji Validitas Variabel Kepuasan Kerja (Y) Item-Total Statistics

\begin{tabular}{|lrrrrr|}
\hline & $\begin{array}{c}\text { Scale Mean if } \\
\text { Item Deleted }\end{array}$ & $\begin{array}{c}\text { Scale } \\
\text { Variance if } \\
\text { Item Deleted }\end{array}$ & $\begin{array}{c}\text { Corrected } \\
\text { Item-Total } \\
\text { Correlation }\end{array}$ & $\begin{array}{c}\text { Squared } \\
\text { Multiple } \\
\text { Correlation }\end{array}$ & $\begin{array}{c}\text { Cronbach's } \\
\text { Alpha if Item } \\
\text { Deleted }\end{array}$ \\
\hline Y1 & 41.25 & 5.399 & .426 & .458 & .672 \\
Y2 & 41.14 & 5.624 & .321 & .509 & .691 \\
Y3 & 41.19 & 5.606 & .327 & .421 & .690 \\
Y4 & 41.00 & 5.421 & .461 & .482 & .667 \\
Y5 & 41.08 & 5.625 & .332 & .468 & .689 \\
Y6 & 41.19 & 5.343 & .448 & .489 & .668 \\
Y7 & 41.06 & 5.483 & .402 & .439 & .677 \\
Y8 & 41.17 & 5.405 & .419 & .532 & .673 \\
Y9 & 41.09 & 5.821 & .241 & .576 & .704 \\
Y10 & 41.01 & 5.802 & .270 & .260 & .698 \\
\hline
\end{tabular}




\begin{tabular}{|cccc|}
\hline No & $\mathrm{r}_{\text {hitung }}$ & $\mathrm{r}_{\text {tabel }}$ & Keterangan \\
\hline 1 & 0.426 & 0.224 & Valid \\
2 & 0.321 & 0.224 & Valid \\
3 & 0.327 & 0.224 & Valid \\
4 & 0.461 & 0.224 & Valid \\
5 & 0.332 & 0.224 & Valid \\
6 & 0.448 & 0.224 & Valid \\
7 & 0.402 & 0.224 & Valid \\
8 & 0.419 & 0.224 & Valid \\
9 & 0.241 & 0.224 & Valid \\
10 & 0.270 & 0.224 & Valid \\
\hline
\end{tabular}

\section{Uji Realibilitas}

Tabel 4. Hasil Uji Reliabilitas Variabel Kepempimpinan kewirausahaan $\left(\mathrm{X}_{1}\right)$

\begin{tabular}{|rrrr|}
\hline ronbach's Alpha & nbach's Alpha Based on Standardized Items & N of Items & \\
\hline .745 & .744 & 10 \\
\hline
\end{tabular}

Tabel 5. Hasil Uji Reliabilitas Variabel Motivasi $\left(\mathbf{X}_{2}\right)$

\begin{tabular}{|rrrr|}
\hline Cronbach's Alpha & $\begin{array}{c}\text { Cronbach's Alpha Based on Standardized } \\
\text { Items }\end{array}$ & N of Items \\
\hline .697 & & .706 & 10 \\
\hline
\end{tabular}

Tabel 6. Hasil Uji Reliabilitas Variabel Kepuasan Kerja (Y)

\begin{tabular}{|rrrr|}
\hline Cronbach's Alpha & $\begin{array}{c}\text { Cronbach's Alpha Based on } \\
\text { Standardized Items }\end{array}$ & N of Items \\
\hline .706 & & .706 & 10 \\
\hline
\end{tabular}

Tabel 7.Perbandingan Nilai Alpha dengan $\mathbf{r}_{\text {tabel }}$

\begin{tabular}{|cccc|}
\hline Variabel & $\begin{array}{c}\text { Nilai } \\
\text { Conbach's }\end{array}$ & $\begin{array}{c}\text { rtabel } \\
(\alpha ; 0.05 . \mathrm{df} 77)\end{array}$ & Keterangan \\
\hline Kepemimpinan & 0.745 & 0.600 & Reliabel \\
Motivasi & 0.697 & 0.600 & Reliabel \\
& & & \\
Kepuasan Kerja & 0.706 & 0.600 & Reliabel \\
& & & \\
\hline
\end{tabular}




\section{B. Uji Asumsi Klasik}

Uji Normalitas

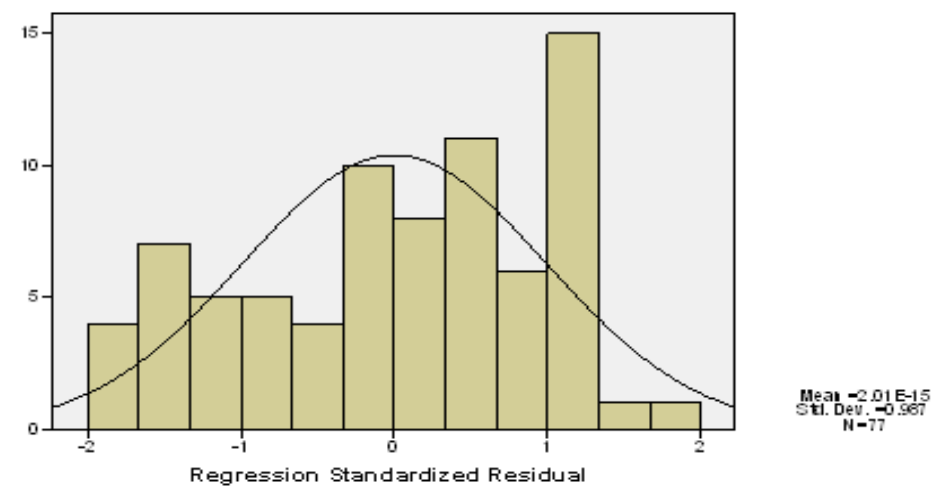

Gambar 1.Histrogram Variabel Kepuasan Kerja

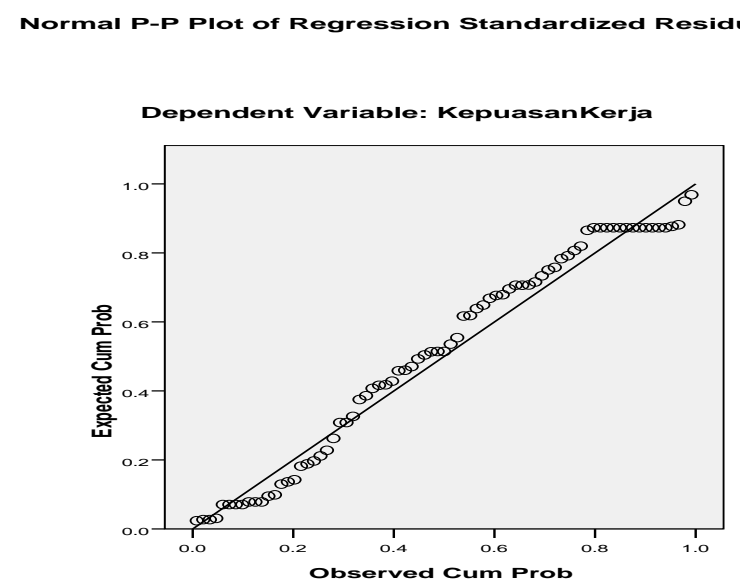

Gambar 2.Normal P-P of Regresi 


\section{Uji Multikolinieritas}

\section{Tabel 8. Uji Multikolinieritas}

Coefficients ${ }^{a}$

\begin{tabular}{|ll|r|r|}
\hline \multirow{2}{*}{ Model } & \multicolumn{2}{|c|}{ Collinearity Statistics } \\
\cline { 3 - 4 } & & Tolerance & \multicolumn{1}{c|}{ VF } \\
\hline 1 & Kepemimpinan & .854 & 1.171 \\
& Motivas i & .854 & 1.171 \\
\hline
\end{tabular}

a. Dependent Variable: KepuasanKerja

Dari tabel coefficient diatas menunjukan bahwa nilai VIF variabel $\mathrm{X}_{1}$ dan $\mathrm{X}_{2}$ diatas adalah 1.171 yang berarti $<10$, dilihat dari nilai tolerance, nilai tolerance kedua variabel mendekati angka 1.

\section{Uji Heteroskedatisitas}

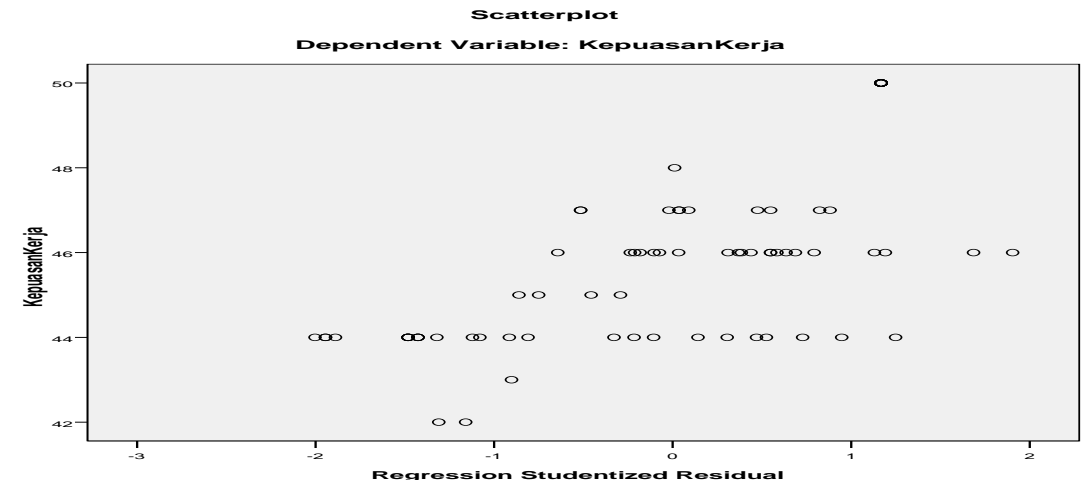

\section{Uji Autokorelasi}

Gambar 3. Scaterplot

Tabel 9.Uji Autokorelasi Model Summary(b)

\begin{tabular}{|l|r|r|r|r|r|}
\hline Model & R & R Square & $\begin{array}{c}\text { Adjusted } \\
\text { R Square }\end{array}$ & $\begin{array}{c}\text { Std. Error of } \\
\text { the Estimate }\end{array}$ & $\begin{array}{c}\text { Durbin- } \\
\text { Watson }\end{array}$ \\
\hline 1 & $.723(\mathrm{a})$ & .522 & .509 & 1.620 & 1.280 \\
\hline
\end{tabular}

a Predictors: (Constant), Kepemimpinan, Motivasi

b Dependent Variable: KinerjaKaryawan

C. Uji Hipotesis

Pengaruh Kepemimpinan kewirausahaan $\left(\mathrm{X}_{1}\right)$ Terhadap Kepuasan Kerja (Y)

\section{Uji Regresi}

Tabel 10.Regresi Linier Berganda Coefficients ${ }^{\mathrm{a}}$

\begin{tabular}{|cccccc|}
\hline Model & \multicolumn{2}{c}{$\begin{array}{c}\text { Unstandardized } \\
\text { Coefficients }\end{array}$} & $\begin{array}{c}\text { Standardized } \\
\text { Coefficients }\end{array}$ & T & Sig. \\
\hline \multirow{3}{*}{1 (Constant) } & Std. & Beta & B & Etd. \\
& 15,742 & 3,386 & & 4,649 &, 000 \\
\hline
\end{tabular}




\begin{tabular}{|llllll|}
\hline $\begin{array}{l}\text { Kepemimpinan } \\
\text { kewirausahaan }\end{array}$ &, 646 &, 072 &, 718 & 8,922 &, 000 \\
\hline
\end{tabular}

Dependent Variable : Kepuasan Kerja

$\mathrm{Y} \quad$ : Kepemimpinan kewirausahaan $\left(\mathrm{X}_{1}\right)$

a $: 15.742$

$\mathrm{bX}_{2}: 0.646$

Sehingga dinyatakan dalam bentuk persamaan regresi sebagai berikut :

$\mathrm{Y}=\mathrm{a}+\mathrm{bX} 1$

$\mathrm{Y}=15.742+0.646 \mathrm{X}_{1}$

Dari hasil persamaan regresi di atas menunjukkan jika kepemimpinan kewirausahaan $\left(\mathrm{X}_{1}\right)$ nilainya adalah 0 (nol) maka kepuasan kerja $(\mathrm{Y})$ adalah 15.742 Sedangkan koefisien regresi kepemimpinan kewirausahaan $\left(\mathrm{X}_{1}\right)$ sebesar 0.646 menunjukkan bahwa setiap penambahan satu satuan kepemimpinan kewirausahaan akan meningkatkan kepuasan kerja sebesar 15.742 .

Koefisien Determinasi (KD)

Tabel 11. Koefisien Korelasi Antara Kepemimpinan Kewirausahaan Terhadap Kepuasan Kerja

\begin{tabular}{|lcccc|}
\hline Model & $\mathrm{R}$ & $\mathrm{R}$ & $\begin{array}{c}\text { Adjusted R } \\
\text { Square }\end{array}$ & $\begin{array}{c}\text { Std. Error of the } \\
\text { Square }\end{array}$ \\
\hline 1 &, $718(\mathrm{a})$ &, 515 &, 508 & 1,621 \\
\hline
\end{tabular}

a. Predictors : (Constant), Kepemimpinan kewirausahaan

b. Dependent Variable: Kepuasan Kerja

Berdasarkan hasil analisis data di atas diperoleh nilai koefisien korelasi R sebesar 0.718. Artinya terdapat pengaruh yang baik antara kepemimpinan kewirausahaan $\left(\mathrm{X}_{1}\right)$ terhadap kepuasan kerja $(\mathrm{Y})$. Sedangkan koefisien determinan (KD) yang dilihat dari R Square $=0.515$. Hal ini berarti kontribusi kepemimpinan kewirausahaan $\left(\mathrm{X}_{1}\right)$ terhadap kepuasan kerja $(\mathrm{Y})$ adalah $51.5 \%$ sedangkan selebihnya $48.5 \%$ ditentukan oleh faktor-faktor lain seperti budaya kerja, disiplin pegawai, lingkungan kerja, dan lain sebagainya yang tidak diteliti .

\section{Uji t}

Hipotesis yang diajukan dalam penelitian ini adalah sebagai berikut:

a. Ho : $\beta=0$ Tidak terdapat pengaruh yang positif kepemimpinan kewirausahaan terhadap kepuasan kerja karyawan

b. Ha : $\beta \neq 0$ Terdapat pengaruh yang positif kepemimpinan kewirausahaan terhadap kepuasan kerja karyawan

Tingkat signifikansi $\alpha=0.05$

$$
\text { Statistik uji } t_{\text {hitung }}=\pi r^{2}=\frac{b}{s b} t_{\text {hitung }}=4.649
$$

Daerah penolakan :

Ho ditolak jika $\mathrm{t}$ hitung $>\mathrm{t}_{\text {tabel }}$ dimana $\mathrm{t}_{\text {tabel }}=\alpha ;(\mathrm{n}-2)=\mathrm{t}_{0.05 ; 75}=0.05 ; 75=$ 1.992 . 


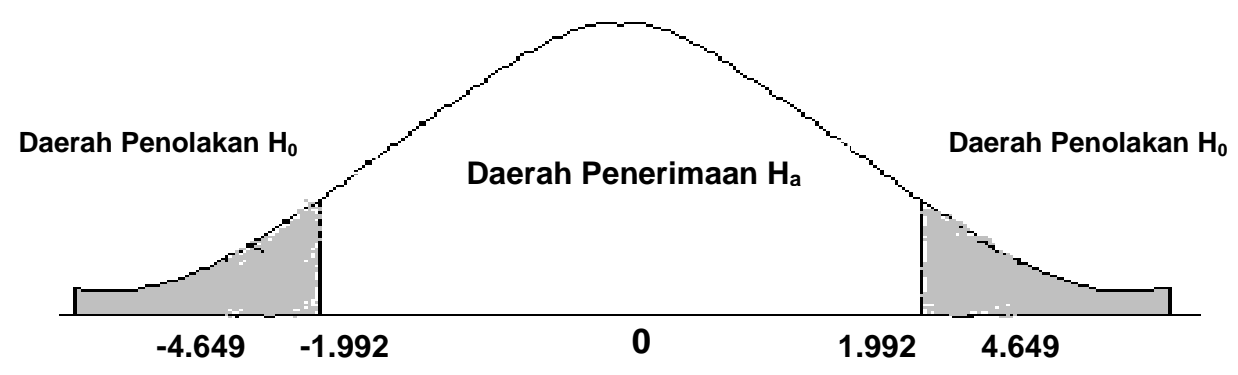

Kesimpulan :

Oleh karena $\mathrm{t}_{\text {hitung }}=4.649>\mathrm{t}$ tabel $=1.992$ pada tingkat sigifikansi 95\% dan $\mathrm{n}-2=75$ maka, Ho ditolak yang artinya terdapat pengaruh kepemimpinan kewirausahaan terhadap kepuasan kerja karyawan pada Universitas Serang Raya.

\section{Pengaruh Motivasi $\left(\mathrm{X}_{2}\right)$ Terhadap Kepuasan Kerja (Y)}

\section{Uji Regresi}

Tabel 12. Regresi Linier Berganda Coefficients ${ }^{\mathbf{a}}$

\begin{tabular}{|c|c|c|c|c|c|}
\hline Model & \multicolumn{2}{|c|}{$\begin{array}{l}\text { Unstandardized } \\
\text { Coefficients }\end{array}$} & $\begin{array}{l}\text { Standardized } \\
\text { Coefficients }\end{array}$ & $\mathrm{T}$ & Sig. \\
\hline 1 (Constant) & $\begin{array}{l}\text { B } \\
36,964\end{array}$ & $\begin{array}{l}\text { Std. Error } \\
2,743\end{array}$ & Beta & $\begin{array}{c}\text { B } \\
13,474\end{array}$ & $\begin{array}{l}\text { Std. } \\
\text { Error } \\
, 000\end{array}$ \\
\hline Motivasi & ,200 &, 061 & ,354 & 3,274 &, 002 \\
\hline
\end{tabular}

Dependent Variable : Kepuasan Kerja

Keterangan :

$\mathrm{Y} \quad$ : Motivasi $\left(\mathrm{X}_{2}\right)$

a $\quad: 36.964$

$\mathrm{bX}_{1}: 0.200$

Sehingga dinyatakan dalam bentukpersamaan regresi sebagai berikut :

$\mathrm{Y}=\mathrm{a}+\mathrm{bX} 2$

$\mathrm{Y}=36.964+0.200 \mathrm{X}_{2}$

\section{Koefisien Determinasi (KD)}

Tabel 13. Koefisien Korelasi Antara Motivasi Terhadap Kepuasan Kerja

\begin{tabular}{|l|c|c|c|c|}
\hline Model & $\mathrm{R}$ & $\begin{array}{c}\mathrm{R} \\
\text { Square }\end{array}$ & $\begin{array}{c}\text { Adjusted R } \\
\text { Square }\end{array}$ & $\begin{array}{c}\text { Std. Error of the } \\
\text { Estimate }\end{array}$ \\
\hline 1 &, $354(\mathrm{a})$ &, 125 &, 113 & 2,117 \\
\hline
\end{tabular}

a. Predictors : (Constant), Motivasi

b. Dependent Variable: Kepuasan Kerja

Berdasarkan hasil analisis data diatas diperoleh nilai koefisien korelasi $\mathrm{R}$ sebesar 0.354 . Artinya terdapat pengaruh yang sedang antara movitasi $\left(\mathrm{X}_{2}\right)$ terhadap kepuasan kerja $(\mathrm{Y})$. Sedangkan koefisien determinan (KD) yang dilihat dari R Square $=0.125$. Hal ini berarti kontribusi movitasi $\left(\mathrm{X}_{1}\right)$ terhadap kepuasan kerja $(\mathrm{Y})$ adalah $12.5 \%$ sedangkan selebihnya $87.5 \%$ ditentukan oleh faktor-faktor lain seperti budaya kerja, disiplin pegawai. 


\section{Uji t}

Hipotesis yang diajukan dalam penelitian ini adalah sebagai berikut:

a. Ho : $\beta=0$ Tidak terdapat pengaruh yang positif motivasi terhadap kepuasan kerja karyawan

b. Ha : $\beta \neq 0$ Terdapat pengaruh yang positif motivasi terhadap kepuasan kerja karyawan

Tingkat signifikansi $\alpha=0.05$

Daerah penolakan :

$$
\text { Statistik uji } t_{\text {hitung }}=\pi r^{2}=\frac{b}{s b} t_{\text {hitung }}=13.474
$$

Ho ditolak jika $\mathrm{t}$ hitung $>\mathrm{t}$ tabel dimana $\mathrm{t}_{\text {tabel }}=\alpha ;(\mathrm{n}-2)=\mathrm{t}_{0.05 ; 75}=0.05 ; 75=$ 1.992 .

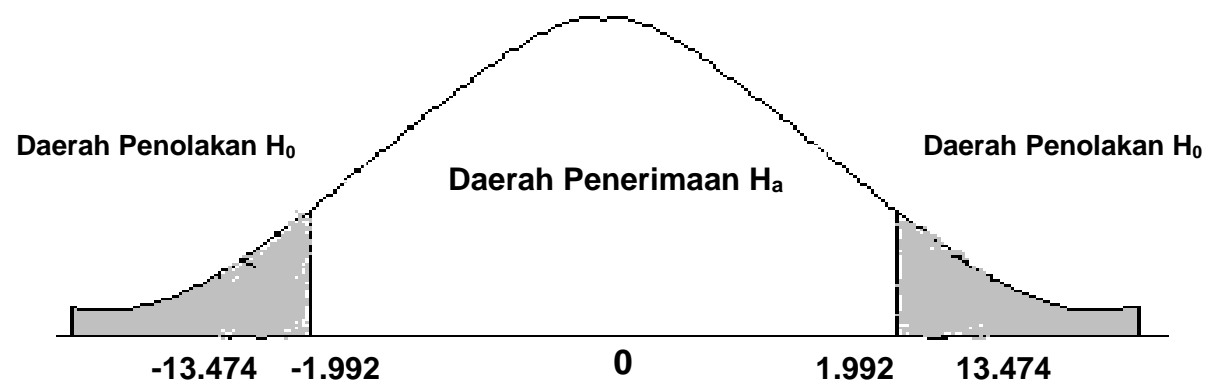

Kesimpulan :

Oleh karena $\mathrm{t}$ hitung $=13.474>\mathrm{t}$ tabel $=1.992$ pada tingkat sigifikansi 95\% dan $\mathrm{n}-2=75$ maka, Ho ditolak yang artinya terdapat pengaruh motivasi terhadap kepuasan kerja karyawan pada Universitas Serang Raya .

Analisis di atas menunjukkan bahwa hasil pengujian hipotesis menunjukkan bahwa motivasi mempunyai pengaruh positif dengan kepuasan kerja, pengaruh motivasi terhadap kepuasan kerja karyawan kerja pada Universitas Serang Raya, yaitu dengan koefisien korelasi sebesar 0.125 dengan $\alpha$ $=0.05$ dengan demikian kontribusi variabel motivasi terhadap kepuasan kerja karyawan pada Universitas Serang Rayasebesar $15.5 \%$.

Pengaruh Kepemimpinan Kewirausahaan (X1) dan Motivasi $\left(\mathrm{X}_{2}\right)$ Terhadap Kepuasan Kerja (Y)

\section{Uji Regresi}

Tabel 14.Regresi Linier Berganda

Coefficients $^{\mathbf{a}}$

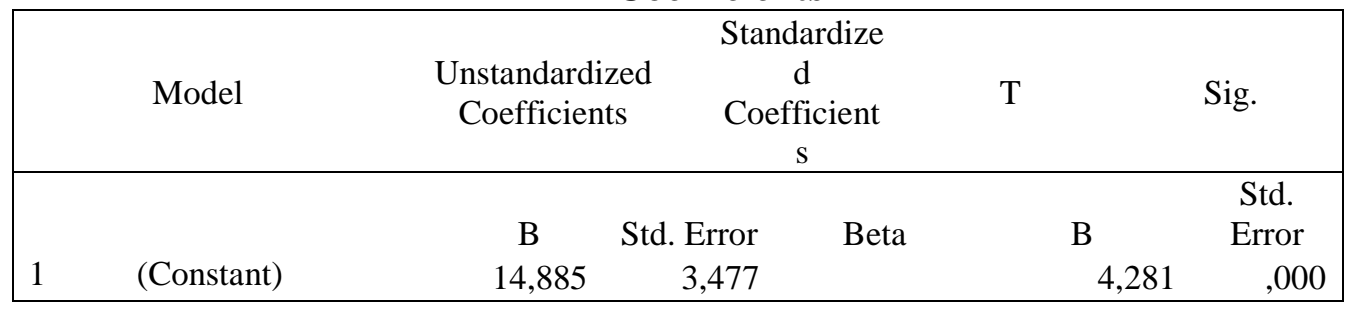




\begin{tabular}{|llllll|}
\hline Kepemimpinan &, 614 &, 078 &, 682 & 7,844 &, 000 \\
Motivasi &, 053 &, 049 &, 093 & 1.068 &, 289 \\
\hline
\end{tabular}

Dependent Variable : Kepuasan Kerja

Keterangan :

Y : Kepuasan kerja

a $: 14.885$

$\mathrm{bX}_{1}: 0.614$

$\mathrm{bX}_{2}: 0.053$

Sehingga dinyatakan dalam bentuk persamaan regresi sebagai berikut :

$\mathrm{Y}=\mathrm{a}+\mathrm{b} \mathrm{X}_{1}+\mathrm{bX} \mathrm{X}_{2}$

$\mathrm{Y}=14.885+0.614 \mathrm{X}_{1}+0.053 \mathrm{X}_{2}$

Dari hasil persamaan regresi di atas menunjukkan jika kepemimpinan kewirausahaan $\left(\mathrm{X}_{1}\right)$ nilainya adalah 0 (nol) maka kepuasan kerja $(\mathrm{Y})$ adalah 14.885 Sedangkan koefisien regresi kepemimpinan $\left(\mathrm{X}_{1}\right)$ sebesar 0.614 menunjukkan bahwa setiap penambahan satu satuan kepemimpinan kewirausahaan akan meningkatkan kepuasan kerja sebesar 14.885. Jika motivasi $\left(\mathrm{X}_{2}\right)$ nilainya adalah 0 (nol) maka kepuasan kerja (Y) adalah 14.885 Sedangkan koefisien motivasi $\left(\mathrm{X}_{2}\right)$ sebesar 0.053 menunjukkan bahwa setiap penambahan satu satuan kepemimpinan kewirausahaan akan meningkatkan kepuasan kerja (Y) sebesar 14.885.

\section{Koefisien Determinasi (KD)}

Tabel 15. Koefisien Korelasi Antara Kepemimpinan Kewirausahaan dan Motivasi terhadap Kepuasan Kerja

\begin{tabular}{|c|c|c|c|c|}
\hline Model & $\mathrm{R}$ & R Square & $\begin{array}{l}\text { Adjusted R } \\
\text { Square }\end{array}$ & Std. Error of the Estimate \\
\hline 1 & ,723(a) &, 522 &, 509 & 1,620 \\
\hline
\end{tabular}

a. Predictors : (Constant), Kepemimpinan, Motivasi

Uji t

b. Dependent Variable: Kepuasan Kerja berikut:

Hipotesis yang diajukan dalam penelitian ini adalah sebagai

a. Ho : $\beta=0$ Tidak terdapat pengaruh yang positif kepemimpinan kewirausahaan dan motivasi terhadap kepuasan kerja karyawan

b. Ha : $\beta \neq 0$ Terdapat pengaruh yang positif kepemimpinan kewirausahaan dan motivasi terhadap kepuasan kerja karyawan

Tingkat signifikansi $\alpha=0.05$

Daerah penolakan :

$$
\text { Statistik uji } t_{\text {hitung }}=\pi r^{2}=\frac{b}{s b} t_{\text {hitung }}=4.281
$$

Ho ditolak jika $\mathrm{t}$ hitung $>\mathrm{t}$ tabel dimana $\mathrm{t}_{\text {tabel }}=\alpha ;(\mathrm{n}-2)=\mathrm{t}_{0.05 ; 75}=0.05 ; 75=$ 1.992.

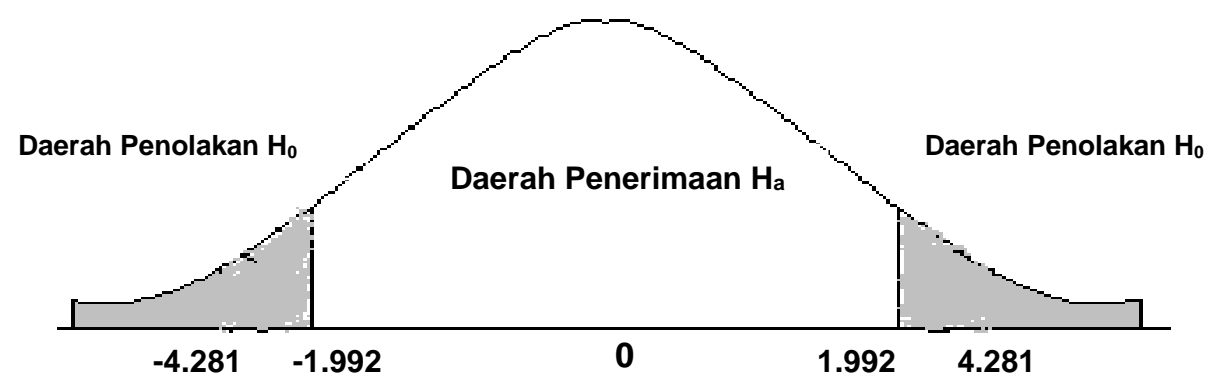




\section{Gambar 5. Daerah Keputusan Uji t}

Oleh karena $\mathrm{t}_{\text {hitung }}=4.281>\mathrm{t}$ tabel $=1.992$ pada tingkat sigifikansi $95 \%$

dan $\mathrm{n}-2=75$ maka, Ho ditolak yang artinya terdapat pengaruh kepemimpinan kewirausahaan dan motivasi terhadap kepuasan kerja karyawan pada Universitas Serang Raya.

Hasil pengujian hipotesis menunjukkan bahwa kepemimpinan kewirausahaan dan motivasi mempunyai pengaruh positif dengan kepuasan kerja karyawan, pengaruh kepemimpinan kewirausahaan dan motivasi terhadap kepuasan kerja karyawan pada Universitas Serang Raya, yaitu dengan koefisien korelasi sebesar 0.552 dengan $\alpha=0.05$ dengan demikian kontribusi variabel kepemimpinan kewirausahaan dan motivasi terhadap kepuasan kerja karyawan pada Universitas Serang Rayasebesar 55.2\%.

\section{Uji Hipotesis (Uji F)}

Tabel 16.Uji F Statistik

$\operatorname{ANOVA}(\mathbf{b})$

\begin{tabular}{|lrrrrr|}
\hline Model & \multicolumn{1}{c}{$\begin{array}{c}\text { Sum of } \\
\text { Squares }\end{array}$} & df & Mean Square & F & Sig. \\
\hline 1 Regression & 212.222 & 2 & 106.111 & 40.446 & $.000(\mathrm{a})$ \\
Residual & 194.141 & 74 & 2.624 & & \\
Total & 406.364 & 76 & & & \\
\hline
\end{tabular}

a Predictors: (Constant), Kepemimpinan kewirausahaan, Motivasi

b Dependent Variable: Kepuasan Kerja

Kriteria Pengujian :

Ho diterima jika $F$ hitung $\leq F$ tabel

Ho ditolak jika $F$ hitung $\geq f_{\text {tabel }}$

Berdasarkan tabel di atas dapat dilihat bahwa nilai $\mathrm{F}_{\text {hitung }}$ sebesar 46.865, nilai tersebut kemudian dibandingkan dengan $\mathrm{F}$ tabel. Apabila tingkat sigifikansi $\alpha$ $=5 \%$, df pembilang $(\mathrm{k}-1)$ atau $(\mathrm{n}-\mathrm{k})$ atau $(77-2)=75$. Maka dapat diperoleh nilai $\mathrm{F}_{\text {tabel }}$ sebesar 3.12.

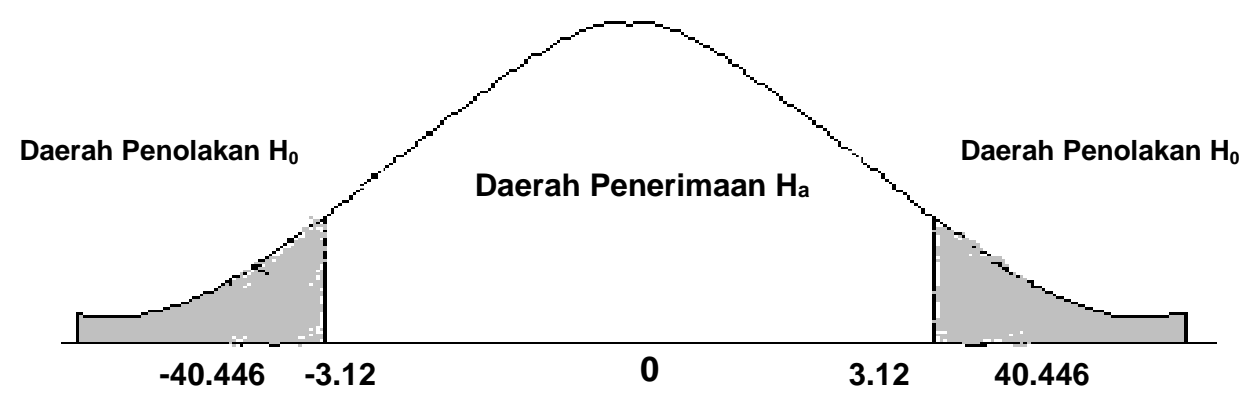

Gambar 6. Daerah Keputusan Uji F 
Dari gambar di atas menunjukkan nilai $\mathrm{F}$ hitung lebih besar dari $\mathrm{F}$ tabel $(40.446>$ 3.12) sehingga Ho ditolak dan $\mathrm{Ha}$ diterima. Berarti terdapat pengaruh kepemimpinan kewirausahaan dan motivasi terhadap kepuasan kerja karyawan pada Universitas Serang Raya .

\section{KESIMPULAN DAN SARAN KESIMPULAN}

Berdasarkan hasil penelitian dan pembahasan, maka dapat diambil suatu simpulan sebagai berikut:

1. Berdasarkan rekapitulasi rata-rata penafsiran sebesar $4.68 \%$ dan angka tersebut termasuk kriteria penilaian sangat baik. Hal ini berarti kepemimpinan kewirausahaan telah dilaksanakan dengan baik walaupun masih belum optimal. Berdasarkan rekapitulasi rata-rata penafsiran sebesar $4.43 \%$ dan angka tersebut termasuk kriteria penilaian sangat baik. Hal ini berarti motivasi telah dilaksanakan dengan sangat baik walaupun masih belum optimal. Berdasarkan rekapitulasi rata-rata penafsiran sebesar $4.59 \%$ dan angka tersebut termasuk kriteria penilaian sangat baik. Hal ini berarti kepuasan kerja telah diperoleh karyawan dengan sangat baik walaupun masih belum optimal.

2. Berdasarkan analisis korelasi antara kepemimpinan kewirausahaan dan motivasi terhadap kepuasan kerja diperoleh sebesar 0.723 Berarti terdapat pengaruh yang baik kepemimpinan kewirausahaan dan motivasi terhadap kepuasan kerja.

Selanjutnya untuk mengetahui besarnya sumbangan variabel kepemimpinan kewirausahaan $\left(\mathrm{X}_{1}\right)$ dan motivasi $\left(\mathrm{X}_{2}\right)$ terhadap variabel kepuasan kerja $(\mathrm{Y})$ digunakan koefisien determinasi dengan nilai perolehan sebesar 52.2\% kepemimpinan kewirausahaan dan motivasi mempunyai pengaruh terhadap kepuasan kerja. Sedangkan sisanya $47.8 \%$ dipengaruhi oleh faktor lain yang tidak diteliti dalam penelitian ini.

Regresi linier sederhana diperoleh persamaan $\mathrm{Y}=14.885+0.614 \mathrm{X}_{1}+$ $0.053 \mathrm{X}_{2}$, jika kepemimpinan kewirausahaan $\left(\mathrm{X}_{1}\right)$ dan motivasi $(\mathrm{X} 2)$ nilainya adalah 0 (nol) maka kepuasan kerja (Y) adalah 14.885. Sedangkan koefisien regresi sebesar 0.614 dan 0.053 menunjukkan bahwa setiap penambahan satu satuan kepemimpinan kewirausahaan $\left(\mathrm{X}_{1}\right)$ dan motivasi $\left(\mathrm{X}_{2}\right)$ akan meningkatkan kepuasan kerja (Y) sebesar 14.885. Perhitungan dari uji $\mathrm{H}_{0}$ ditolak dan $\mathrm{H}_{\mathrm{a}}$ diterima.

\section{SARAN}

Berdasarkan uraian kesimpulan di atas, dapat memberikan beberapa saran yang mudah-mudahan dapat memberikan kontribusi pada peningkatan kepuasan kerja karyawan pada Universitas Serang Rayasebagai berikut:

1. Mengingat kepemimpinan kewirausahaan sangat berpengaruh terhadap kepuasan kerja karyawan maka pihak pimpinan hendaknya menciptakan 
suasana yang berbeda dan memperhatikan terhadap karyawan berkaitan dengan hasil kerja karyawan, penempatan tugas yang telah dibebankan kepada karyawan, perlakuan pimpinan terhadap karyawan, serta lingkungan kerja.

2. Setiap karyawan diharapkan melaksanakan tugas secara profesional dan penuh tanggung jawab sesuai dengan tugas masing-masing guna meningkatkkan kepuasan kerjanya.

\section{DAFTAR PUSTAKA}

Arep, Ishak, dkk.2003, Manajemen Sumber Daya Manusia.. Universitas Trisakti. Jakarta

Arikunto, Suharsimi. 2002 Prosedur Penelitian. Rineka Cipta. Jakarta

As'ad. 2004, Kepemimpinan dan Motivasi. Ghalia Indonesia. Jakarta.

Budiardjo, Miriam, 2003. Dasar-Dasar Ilmu Politik, Jakarta

Daft Richard L. 2007. Management-Manajemen. Edisi 6 Buku 1. Salemba Empat. Jakarta.

Ghozali, Imam. 2007. Aplikasi Analisis Multivariate Dengan Program SPSS. BPUniversitas Diponogoro, Semarang.

Greenberg, Jerald dan Baron, Robert A. 2000. Perilaku Organisasi. Jakarta : Prentice Hall.

Handayaningrat, Soewarno, 2002, Manajemen Personalia dan Sumber Daya Manusia, Cetakan pertama, Liberti. Jakarta

Hasibuan, Malayu, S.P. 2003. Manajemen Dasar, Pengertian dan Masalah. Jakarta : PT Toko Gunung Agung.

Karyadi, M., 2001. Kepemimpinan, Karya Nusantara. Bandung

Labovitz, Sanford dan Robert Hagedorn, 2000. Metode Riset Sosial, Erlangga, Jakarta

Nawawi, Hadari. 2005. Manajemen Sumber Daya Manusia. Gajah Mada University Press. Yogyakarta

Riggio, Ronald E. 2000.Manajemen Kinerja Gramedia Pustaka Utama. Jakarta

Robbin, Stephen P, 2003. Perilaku Organisasi, Edisi Kesembilan, Jilid 2, PT. Indeks Kelompok Gramedia, Jakarta.

Santoso, Singgih. 2007. Statistik Multivariat, PT Gramedia. Jakarta 
Sondang P. Siagian, 2010. Teori \& Praktek Kepemimpinan. PT Rieneka Cipta, Jakarta

Sopiah, 2008, Perilaku Organisasional, C.V Andi Offset. Yogyakarta

Sugiyono. 2007 Metode Penelitian Administrasi, CV Alfabeta. Bandung

Supranto, John, 2000. Statistik-Teori dan Aplikasi, Erlangga. Jakarta

Susanto A.B; Koesnadi Kardi, 2003. Pemimpinan dan Kepemimpinan.Raja. Grafindo Persada. Jakarta.

Sutrisno Hadi, 2004. Statistik Jilid 2, Andi Offset. Yogyakarta

Siagian, Sondang P., 1992 b, Peranan Staf Dalam Management, Bandung : Gunung Agung.

Sutrisno, Edy. 2010. Manajemen Sumber Daya Manusia; PT Prenada Media. Group. Jakarta

Thoha, Miftah. 2003. Perspektif Perilaku Birokrasi. PT. Raja Grafindo Persada. Jakarta

Tangkilisan, H.N.S., 2005, Manajemen Publik, Jakarta : Grasindo

Wibowo. 2010. Manajemen Kinerja. PT. Rajagrafindo Persada, Jakarta.

Yatim Riyanto, 2001 Metodologi Penelitian Pendidikan, SIC Sura

Naniek Utami Handayani, dkk. (2018). Faktor Penentu Kesadaran Konsumen Dalam Pembelian Produk Kertas Bertanda Eco-Label. Jurnal MIX: Jurnal Ilmiah Manajemen, Volume 8, No. 3, Okt 2018. p. 477 - 503. ISSN : 2088-1231. E-ISSN: 2460-5328. DOI: dx.doi.org/10.22441/mix.2018.v8i3.003 